\title{
Correction: Huang, H.-M., et al. Effects of Sapindus mukorossi Seed Oil on Skin Wound Healing: In Vivo and In Vitro Testing. Int. J. Mol. Sci. 2019, 20, 2579
}

\author{
Chang-Chih Chen ${ }^{1,2}$, Chia-Jen Nien ${ }^{3}$, Lih-Geeng Chen ${ }^{4}$, Kuen-Yu Huang ${ }^{3}$, Wei-Jen Chang ${ }^{5}$ \\ and Haw-Ming Huang $3,5, *$ (D) \\ 1 Emergency Department, Mackay Momorial Hospital, Taipei 110, Taiwan \\ 2 Medical School, Mackay Medical College, New Taipei City 252, Taiwan \\ 3 Graduate Institute of Biomedical Optomechatronics, College of Biomedical Engineering, Taipei Medical \\ University, Taipei 110, Taiwan \\ 4 Department of Microbiology, Immunology and Biopharmaceuticals, College of Life Sciences, \\ National Chiayi University, Chiayi 600, Taiwan \\ 5 School of Dentistry, College of Oral Medicine, Taipei Medical University, Taipei 110, Taiwan \\ * Correspondence: hhm@tmu.edu.tw; Tel.: +886-2-2736-1661 (ext. 5128)
}

Received: 23 August 2019; Accepted: 23 August 2019; Published: 26 August 2019

The authors are sorry to report that some of the HPLC data reported in their recently published paper [1] were incorrect. The data for $\beta$-sitosterol and $\delta$-tocopherol was mismatched. In addition, the data of $\beta$-sitosterol were obtained from a $1 \%$ oil sample. Consequently, the authors wish to make the following corrections to the paper: On page 4, Section 2.2 HPLC Analysis, line 4, and page 12, Conclusion, line 5: The total amount of $\beta$-sitosterol and $\delta$-tocopherol in the $S$. mukorossi seed oil was $73.9 \pm 23.6 \mu \mathrm{g} / \mathrm{mL}$ (in $1 \%$ oil) and $232.64 \pm 4.5 \mu \mathrm{g} / \mathrm{mL}$, respectively.

There was one calculation error when the unit was changed from " $\mu \mathrm{g} / \mathrm{mL}$ " to "\%": On page 8, paragraph 4, line 7, the sentence "S. mukorossi seed oil are $7.3 \%$ and $0.235 \%$, respectively. These values are much higher than the analogous quantities in shea butter $(0.8 \%$ for sterols and $0.08 \%$ for tocopherols)" should be "S. mukorossi seed oil are $0.73 \%$ and $0.023 \%$, respectively. These values are much higher than the analogous quantities in shea butter $(0.5 \%$ for total sterols and $0.08 \%$ for total tocopherols)".

These changes have no material impact on the conclusions of our paper. We apologize to our readers.

Conflicts of Interest: The authors declare no conflict of interest.

\section{Reference}

1. Chen, C.-C.; Nien, C.-J.; Chen, L.-G.; Huang, K.-Y.; Chang, W.-J.; Huang, H.-M. Effects of Sapindus mukorossi Seed Oil on Skin Wound Healing: In Vivo and in Vitro Testing. Int. J. Mol. Sci. 2019, 20, 2579. [CrossRef] [PubMed]

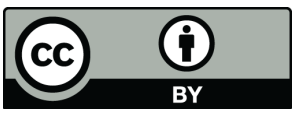

(C) 2019 by the authors. Licensee MDPI, Basel, Switzerland. This article is an open access article distributed under the terms and conditions of the Creative Commons Attribution (CC BY) license (http://creativecommons.org/licenses/by/4.0/). 